\title{
Surface chemistry of alanine on Ni\{111\}
}

Article

Accepted Version

Nicklin, R. E. J., Cornish, A., Shavorskiy, A., Baldanza, S., Schulte, K., Liu, Z., Bennett, R. A. and Held, G. (2015) Surface chemistry of alanine on Ni\{111\}. Journal of Physical Chemistry C, 119 (47). pp. 26566-26574. ISSN 1932-7447 doi: https://doi.org/10.1021/acs.jpcc.5b08814 Available at https://centaur.reading.ac.uk/46747/

It is advisable to refer to the publisher's version if you intend to cite from the work. See Guidance on citing.

To link to this article DOI: http://dx.doi.org/10.1021/acs.jpcc.5b08814

Publisher: American Chemical Society

All outputs in CentAUR are protected by Intellectual Property Rights law, including copyright law. Copyright and IPR is retained by the creators or other copyright holders. Terms and conditions for use of this material are defined in the End User Agreement.

\section{www.reading.ac.uk/centaur}

\section{CentAUR}

Central Archive at the University of Reading

Reading's research outputs online 


\section{Surface Chemistry of Alanine on Ni\{111\}}

2 Richard E. J. Nicklin, ${ }^{\dagger}$ Alix Cornish, ${ }^{\dagger}$ Andrey Shavorskiy, ${ }^{\ddagger}$ Silvia Baldanza, ${ }^{\dagger}$ Karina Schulte, ${ }^{\S}$ Zhi Liu, ${ }^{\ddagger}$ ${ }_{3}$ Roger A. Bennett, ${ }^{\dagger}$ and Georg Held ${ }^{*},, \|$

$4{ }^{\dagger}$ Department of Chemistry, University of Reading, Reading RG6 6AD, U.K.

$5{ }^{\ddagger}$ Advanced Light Source, Lawrence Berkeley National Laboratory, Berkeley, California 94720, United States

$6{ }^{\S}$ MAX-lab, Lund University, 22100 Lund, Sweden

7 "Diamond Light Source Ltd, Oxfordshire OX11 0DE, U.K.

9 ABSTRACT: The adsorption of L-alanine on Ni\{111\} has been studied as a model of enantioselective heterogeneous catalysts. Synchrotron-based X-ray photoelectron spectroscopy and near-edge X-ray absorption fine structure (NEXAFS) spectroscopy were used to determine the chemical state, bond coordination, and out-of-plane orientation of the molecule on the surface. Alanine adsorbs in anionic and zwitterionic forms between 250 and $\approx 320 \mathrm{~K}$. NEXAFS spectra exhibit a strong angular dependence of the $\pi^{*}$ resonance associated with the carboxylate group, which is compatible with two distinct orientations with respect to the surface corresponding to the bidentate and
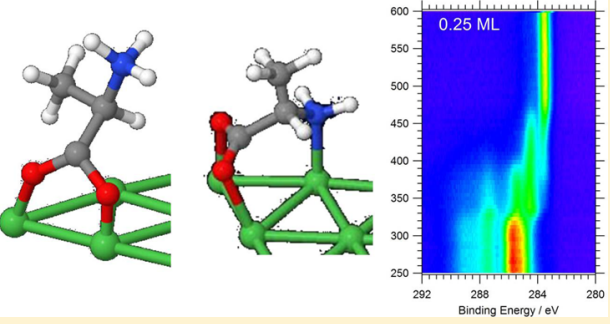
$\approx 300 \mathrm{~K}$, with decomposition occurring in a multistep process up to $\approx 450 \mathrm{~K}$. Comparison with previous studies of amino acid adsorption on metal surfaces shows that this is among the lowest decomposition temperatures found so far and lower than typical temperatures used for hydrogenation reactions where modified Ni catalysts are used.

23 Amino acid adsorption on metals is a burgeoning field of research 24 due to its relevance to chemical sensing, biomedical research, and 25 enantioselective catalysis. Heterogeneous enantioselective catal26 ysis using alanine as a chiral modifier for $\mathrm{Ni}$ has been known since $271962 .{ }^{1}$ The best studied reaction in this context is the 28 enantioselective hydrogenation of methyl acetoacetate, ${ }^{2-4}$ with 29 surface sensitivity results pointing to the involvement of the 30 low-Miller-index planes. ${ }^{5,6}$

31 The orientation and bonding of amino acids on transition32 metal surfaces has been probed by a variety of techniques, 33 notably low-energy electron diffraction (LEED), temperature34 programmed desorption (TPD), near-edge X-ray absorption 35 fine structure (NEXAFS) spectroscopy, reflection absorption 36 IR spectroscopy (RAIRS), high-resolution electron energy loss 37 spectroscopy (HREELS), photoelectron diffraction (PhD), 38 scanning tunneling microscopy (STM), and X-ray photoelectron 39 spectroscopy (XPS). ${ }^{7-47}$ LEED, NEXAFS, STM, XPS, and PhD 40 have been used to investigate the adsorption of glycine and 41 alanine on $\mathrm{Cu}$ surfaces. It was demonstrated that the adsorbate 42 binds as the anion, adopting a tridentate binding mode on the 43 surface, with single $\mathrm{Cu}$ atoms bonding to both $\mathrm{O}$ atoms 44 and the $\mathrm{N}$ atom. ${ }^{11,19,21,28,46,47}$ This three-point binding has 45 received theoretical support. ${ }^{28,48-51}$ It breaks the surface 46 symmetry and imposes a chiral environment on the surface, a 47 prerequisite for chiral catalysis. ${ }^{72,53}$ For adsorption on $\mathrm{Ni}\{111\}$, 48 however, the work by Ghiringhelli et al. ${ }^{54}$ suggests that alanine 49 will adsorb via the $\mathrm{N}$ atom and a single carboxyl group $\mathrm{O}$ 50 atom (the other $\mathrm{O}$ atom being protonated). Recent work by Baldanza et al. ${ }^{45}$ has highlighted the possibility of a bidentate 51 binding mode for alanine on the $\mathrm{Cu}\{111\}$ surface, where the 52 alanine adsorbs on the surface as the zwitterion, with single $\mathrm{Cu} 53$ atoms bonding to the two $\mathrm{O}$ atoms only.

The present work examines the chemical nature and 55 orientation of the smallest chiral modifier, alanine, bound to 56 the $\mathrm{Ni}\{111\}$ surface. Synchrotron-based XPS and NEXAFS 57 spectroscopy are used to determine the chemical state and out- 58 of-plane orientation of the adsorbed molecules. Temperature- 59 programmed (TP-)XPS experiments were performed to 60 investigate changes in the chemical state and decomposition 61 pathways followed by the molecules upon annealing. The 62 experimental results indicate that alanine initially adsorbs in its 63 anionic form with a tridentate binding mode at low coverages. 64 With increasing coverage, alanine begins to bind as the zwitterion 65 in a bidentate mode, with surface saturation at $0.25 \mathrm{ML}$ and both 66 forms of alanine coexisting on the surface. Desorption and 67 decomposition are seen to begin together at around $300 \mathrm{~K}$, with 68 decomposition occurring in a multistep process below $450 \mathrm{~K} .69$ NEXAFS spectra exhibit strong angular dependence of the $\pi^{*} 70$ resonances associated with the carboxylate group, allowing the 71 establishment of two distinct orientations with respect to the 72 surface, which are presumed to correspond to the bidentate and 73 tridentate binding modes.

Received: September 9, 2015

Revised: October 26, 2015 


\section{EXPERIMENTAL SECTION}

76 The experiments were carried out in two different ultrahigh 77 vacuum (UHV) systems. XPS and NEXAFS experiments were 78 performed at both the UHV endstation of beamline I-311 at the 79 MAXlab Synchrotron Radiation Facility in Lund, Sweden, ${ }^{55}$ and 80 the near-ambient pressure endstation of beamline 9.3.2 at the 81 ALS Synchrotron in Berkeley, CA, USA, ${ }^{56}$ which are equipped 82 with Scienta SES200 and 4000R-Hipp electron energy analysers, 83 respectively.

84 Standard procedures including $\mathrm{Ar}^{+}$ion sputtering and a final 85 annealing step to $1000 \mathrm{~K}$ in UHV were applied for sample 86 cleaning. Cleanliness was checked by XPS. The sample 87 temperature was measured by means of K-type thermocouples 88 spot-welded to the sample. L-Alanine (>98\% from Aldrich) was 89 dosed by using a home-built evaporator for organic molecules. 90 The evaporator design consists of one or more resistively heated 91 stainless steel crucibles each containing a glass tube filled with 92 the organic material to be evaporated. K-type thermocouples are 93 attached to the crucibles for accurate and reproducible 94 temperature control. L-Alanine was dosed by heating the crucible 95 to temperatures between 413 and $428 \mathrm{~K}$.

96 For the experiments performed at MAXLab and ALS, L97 alanine was adsorbed at sample temperatures of 250 and $300 \mathrm{~K}$, 98 respectively. XP spectra in the $\mathrm{C} 1 \mathrm{~s}, \mathrm{~N} 1 \mathrm{~s}$, and $\mathrm{O} 1 \mathrm{~s}$ regions were 99 recorded using photon energies of 410,525 , and $650 \mathrm{eV}$, 100 respectively, and a pass energy of $50 \mathrm{eV}$. Spectra of the Fermi 101 edge were measured after each change in the beamline settings 102 with the same monochromator and analyzer parameters (photon 103 energy, pass energy) to calibrate the offset of the binding 104 energies. In order to study the temperature dependence of the 105 absorbed alanine layers, fast XP spectra were recorded at a rate of 106 typically $27 \mathrm{~s}$ per spectrum while annealing the sample at a 107 constant rate of $0.2 \mathrm{~K} \mathrm{~s}^{-1}$ ( $5.4 \mathrm{~K}$ per spectrum).

108 NEXAFS spectra at the $\mathrm{O}, \mathrm{C}$, and $\mathrm{N}$ K-edges were recorded at 109 MAXlab in Auger-yield mode using the same analyzer as for XPS 110 and with the photon beam at angles of $0^{\circ}$ or $65^{\circ}$ with respect to 111 the surface normal. $\mathrm{O}, \mathrm{C}$, and $\mathrm{N}$ K-edge spectra were recorded 112 in the kinetic energy ranges 490-525 eV, 250-295 eV, and $113365-390 \mathrm{eV}$, while the photon energy was scanned from 525 to $114560 \mathrm{eV}, 280$ to $310 \mathrm{eV}$, and 395 to $415 \mathrm{eV}$, respectively, in steps of $1150.15 \mathrm{eV}$. The photon flux, $I_{0}$, was recorded by measuring the 116 current from a photodiode inserted into the beamline. NEXAFS 117 spectra were measured for the clean surface and after adsorption 118 of L-alanine at $250 \mathrm{~K}$. The data presented here are integrated 119 over a smaller kinetic energy range of 511.3-513.3 eV (262.5$120265.0 \mathrm{eV}, 380.5-383.5 \mathrm{eV}$ ) in order to avoid artificial structures 121 due to photoemission peaks. These spectra are then divided by $I_{0}$, 122 normalized with respect to the pre-edge (low photon energy) 123 background, and have the clean-surface spectra subtracted, which 124 were treated in the same way. In a final step, the spectra were 125 normalized with respect to the postedge (high photon energy) 126 background.

\section{RESULTS AND DISCUSSION}

128 Chemical State. Figure 1 shows the XP spectra recorded in 129 the $\mathrm{C} 1 \mathrm{~s}, \mathrm{~N} \mathrm{1s}$, and $\mathrm{O}$ 1s regions after L-alanine deposition onto 130 the surface at 250 and $300 \mathrm{~K}$. Coverage calibration was per131 formed via comparison of the $\mathrm{O} 1 \mathrm{~s}$ and $\mathrm{C} 1 \mathrm{~s}$ XPS signal areas with 132 those for a saturated $\mathrm{CO}$ layer of known coverage $\Theta=0.57 \mathrm{ML}^{57}$ 133 using an excitation energy of $950 \mathrm{eV}$ (not shown). With lower 134 photon/kinetic energies, photoelectron (as used for recording 135 the data in Figure 1) diffraction can lead to variations in peak intensities which are not proportional to the surface coverage. 136 The coverage, $\Theta$, is subsequently expressed in terms of L-alanine 137 molecules per surface $\mathrm{Ni}$ atom, assuming that all of the carbon 138 and oxygen present on the surface are incorporated in alanine 139 molecules. Strong photoelectron diffraction effects are seen at 140 lower photon energies, with relative peak intensities varying 141 significantly. Whereas previous work on $\mathrm{Cu}$ surfaces has shown 142 relatively slight change in overall spectral structure with coverage, 143 the C 1s spectra shown in Figure 1 show notable variation 144 with coverage within the $283-286 \mathrm{eV}$ binding energy envelope. 145 This is attributed to the generation of decomposition fragments 146 at low coverages of alanine, and their presence complicates the 147 fitting of the spectra and the calibration of the surface coverage of 148 intact alanine.

149

Figure 1a,d shows C 1s spectra recorded after dosing at 250150 and $300 \mathrm{~K}$, respectively. Six distinct peaks can be identified at low 151 coverages, with binding energies of 283.5, 284.5, 285.3, 285.7, 152 287.3, and 288.9-289.1 eV (see Tables S1 and S2 in the 153 Supporting Information for a list of fitting parameters). As 154 coverage increases above $0.11 \mathrm{ML}$ at $250 \mathrm{~K}(0.20 \mathrm{ML}$ at $300 \mathrm{~K}), 155$ the peak at $285.3 \mathrm{eV}$ appears to shift to $285.0 \mathrm{eV}$, while, in the 156 multilayer, the peak at $285.7 \mathrm{eV}$ shifts to $286.1 \mathrm{eV}$. At multilayer 157 coverage, only three peaks can be clearly resolved at 289.1, 287.3, 158 and $286.1 \mathrm{eV}$. The multilayer is only seen to grow for deposition 159 at $250 \mathrm{~K}$; at $300 \mathrm{~K}$, no multilayer could be generated. The two 160 low binding energy peaks have been assigned to decomposition 161 fragments based on previously published results: atomic carbon 162 or $\mathrm{H}_{x} \mathrm{CN}$ are assigned at $283.5 \mathrm{eV}^{58-60}$ and $-\mathrm{C}=\mathrm{C}-$ groups at 163 $284.5 \mathrm{eV} .^{61-67}$ The $285.3 \mathrm{eV}$ peaks incongruously high intensity 164 at low coverage, coupled with its apparent movement to $285.0 \mathrm{eV} 165$ with higher coverage, is consistent with known behavior of CO 166 when coadsorbed with hydrocarbons, ${ }^{57}$ although it should be 167 noted that dehydrogenated $\mathrm{H}_{x} \mathrm{CN}$ species on $\operatorname{Pd}\{111\}$ also 168 generate a $\mathrm{C} 1 \mathrm{~s}$ signal at $285.0 \mathrm{eV}{ }^{68}$ The remaining peaks at 169 $285.7-286.1 \mathrm{eV}, 287.3 \mathrm{eV}$, and $288.9-289.1 \mathrm{eV}$ are assigned in a 170 similar fashion to previous work on $\mathrm{Cu}\{110\}$ and $\mathrm{Cu}\{111\} .^{28,45} 171$ The low coverage $285.7 \mathrm{eV}$ signal is assigned to the superposition 172 of peaks arising from the methyl and $\alpha$-C atoms in the anionic 173 alaninate. At the multilayer coverage, the methyl $\mathrm{C}$ atom peak 174 shifts to $286.1 \mathrm{eV}$. This shift is a result of reduced screening by the 175 metal in the multilayer as opposed to the monolayer, a similar 176 effect being seen for the carboxylate group shifting from 288.9 to 177 $289.1 \mathrm{eV}$. The $287.3 \mathrm{eV}$ peak is assigned to the $\alpha-\mathrm{C}$ atom of 178 zwitterionic alanine (bound to a $-\mathrm{NH}_{3}$ group). 179

Figure $1 \mathrm{~b}$,e shows $\mathrm{N}$ 1s spectra for alanine dosed onto the $\mathrm{Ni} 180$ surface at 250 and $300 \mathrm{~K}$, respectively. Three peaks are observed, 181 at $397.2 \mathrm{eV}$ (only at $300 \mathrm{~K}$ ), $399.7 \mathrm{eV}$, and $401.6 \mathrm{eV}$. These peaks 182 are assigned to a $\mathrm{H}_{x} \mathrm{CN}$ decomposition species, $-\mathrm{NH}_{2}$ from 183 anionic alaninate and $-\mathrm{NH}_{3}^{+}$from zwitterionic alanine.

184

The $\mathrm{O}$ 1s spectra of Figure 1c,f shows two chemical 185 environments, a dominant peak at $531.5 \mathrm{eV}$ and a small feature 186 at $533.5 \mathrm{eV}$. These are assigned to the deprotonated carboxylic 187 acid group and the protonated $-\mathrm{COOH}$, respectively. ${ }^{41}$ The 188 peak at $533.5 \mathrm{eV}$ is only presented above $0.11 \mathrm{ML}$ at $250 \mathrm{~K}$ and 189 above $0.19 \mathrm{ML}$ at $300 \mathrm{~K}$. It is likely that its presence is connected 190 to the abundance of hydrogen on the surface. For submonolayer 191 coverages (i.e., <0.25 ML), the $533.5 \mathrm{eV}$ peak appears to have a 192 fixed relative intensity of $10 \%$ of the main peak at $531.5 \mathrm{eV}, 193$ suggesting a degree of hydrogen bonding between the adsorbed 194 molecules. At coverages above $0.25 \mathrm{ML}$, the O 1s signal shifts to 195 progressively higher binding energies, indicating the decoupling 196 of the carboxylate group from the surface and the formation of 197 the multilayer. The relative intensity of the $533.5 \mathrm{eV}$ signal also 198 

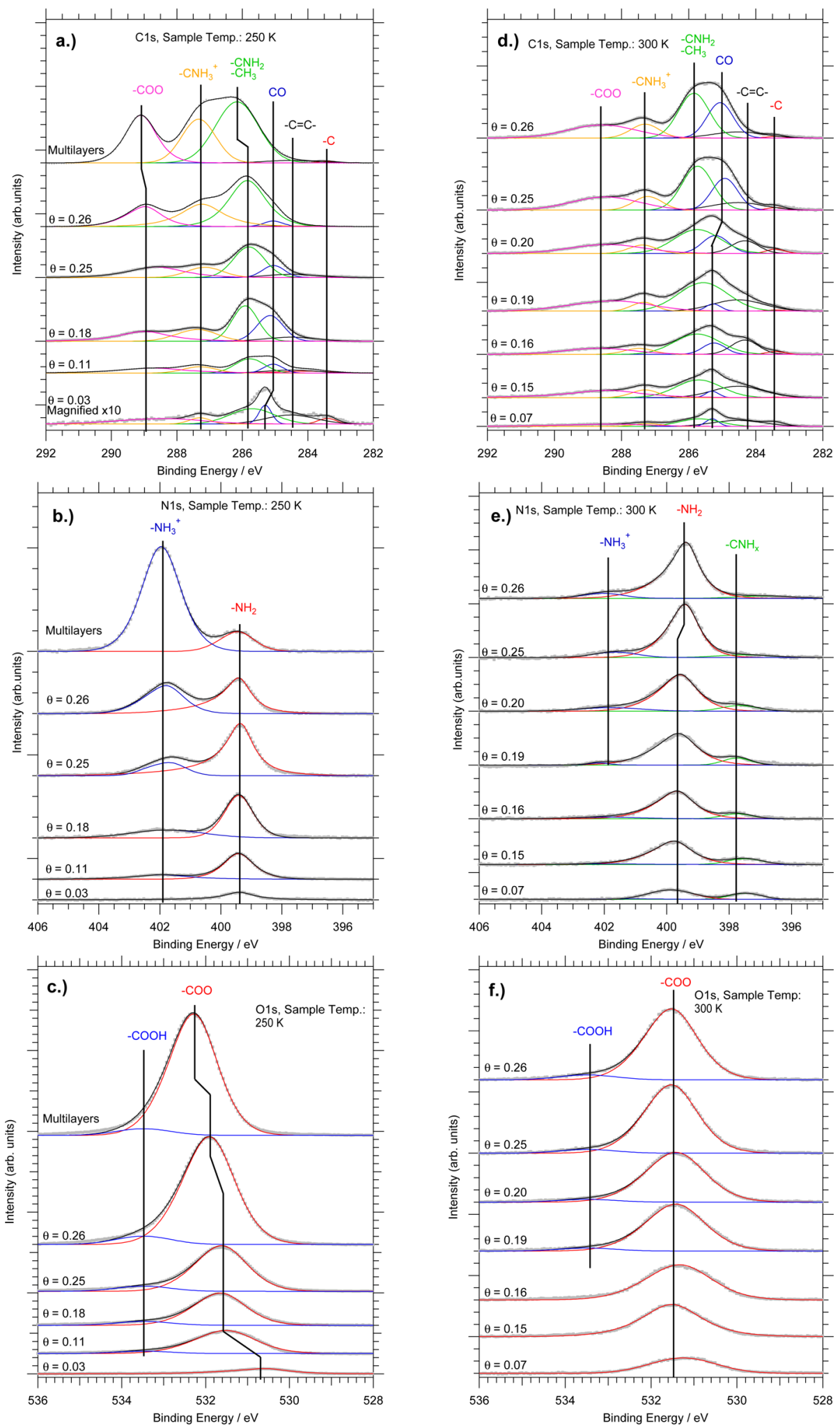

Figure 1. C 1s (a, d), N 1s (b,e), and O 1s (c, f) XP spectra of L-alanine overlayers on Ni\{111\}, recorded at 410, 525 , and $650 \mathrm{eV}$, respectively. Gray dots represent raw data and continuous lines fitted peaks. Spectra $(\mathrm{a}-\mathrm{c})$ adsorbate dosed onto crystal held at $250 \mathrm{~K}$, and (d-f) adsorbate dosed onto crystal held at $300 \mathrm{~K}$.

199 decreases at high coverages, which leads to the conclusion that 200 alanine is deprotonated in the multilayer. Throughout this 201 discussion, it is assumed that the $\mathrm{O} 1 \mathrm{~s}$ signal generated by 202 coadsorbed $\mathrm{CO}$ is masked by the intensity of the signal generated 203 by the alanine.
Figure 2 shows a plot of peak areas (in terms of sur- 204 face coverage) of the $\mathrm{C} 1 \mathrm{~s}$ and $\mathrm{N} 1 \mathrm{~s}$ peaks discussed above 205 against the total alanine surface coverage for adsorption at $250 \mathrm{~K} .206$ The $287.3 \mathrm{eV} \mathrm{C} \mathrm{1s} \mathrm{peak} \mathrm{and} \mathrm{the} 401.6 \mathrm{eV} \mathrm{N}$ 1s peak, which 207 are both associated with zwitterionic alanine, are observed 208 


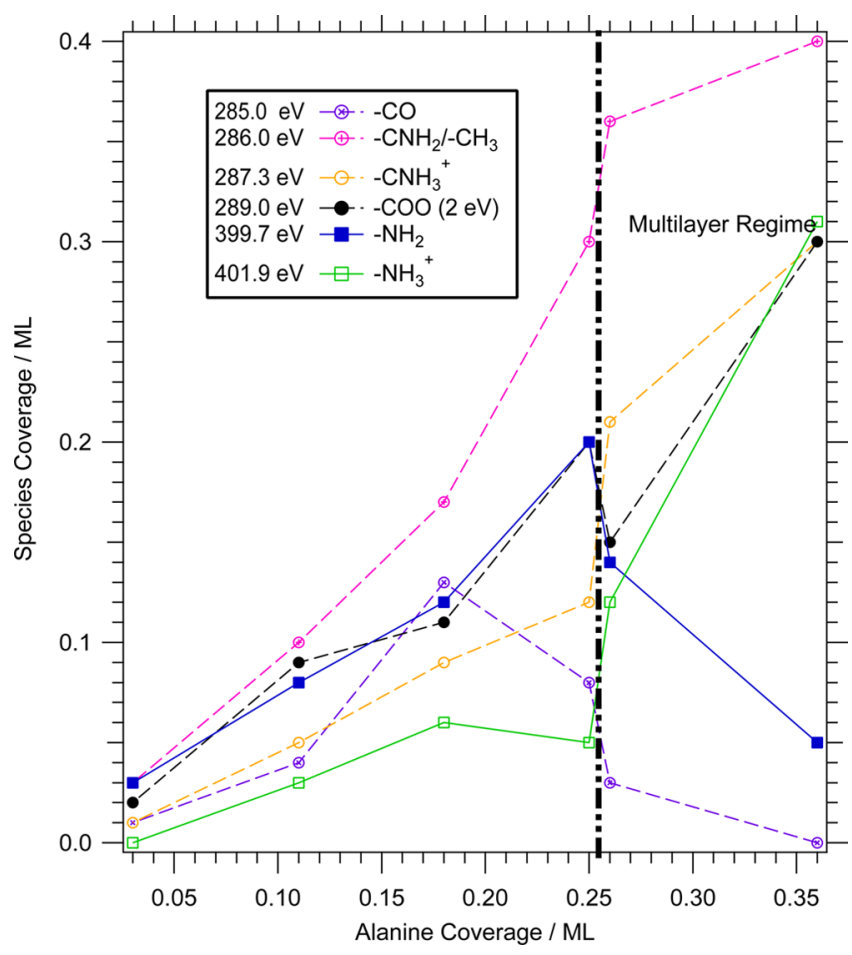

Figure 2. Plot of peak area converted to surface coverage for identified chemical species at varying alanine coverages.

209 well below the onset of multilayer growth. This raises three 210 possibilities:

211

212

213

214

215

216

217

218

219

220

221

222 It appears unlikely that a decomposition product would mimic 223 the zwitterion quite so precisely. On the other hand, the presence 224 of the $287.3 \mathrm{eV}$ peak at very low surface coverages forces us 225 to consider that a fragment may, in fact, be the dominant 226 contributor to this peak in this coverage regime at temperatures 227 above $320 \mathrm{~K}$. Considering the question of multilayer growth 228 before completion of the monolayer, it is noted that the $401.6 \mathrm{eV}$ 229 peak (associated with the zwitterion) begins to grow in the $\mathrm{N} 1 \mathrm{~s}$ $230 \mathrm{XP}$ spectrum at below $\Theta=0.11 \mathrm{ML}$. It seems unlikely that a 231 second layer would begin to form at such a low coverage; 232 however, above $\Theta=0.26 \mathrm{ML}$, the $399.7 \mathrm{eV}$ peak begins to shrink 233 compared to the $401.2 \mathrm{eV}$ peak, suggesting the growth of a 234 second layer over the monolayer, attenuating the $399.7 \mathrm{eV}$ peak 235 signal. We, therefore, favor the third possibility that molecules 236 bound to the surface exist in both the bidentate zwitterionic and 237 the tridentate anionic states at coverages above $0.11 \mathrm{ML}$, with the 238 anionic state being populated first, and second layers beginning 239 to grow at coverages $\geq 0.25 \mathrm{ML}$. Consequently, it is suggested 240 that $0.25 \mathrm{ML}$ corresponds to the saturation coverage for $241 \mathrm{Ni}\{111\}$. This value is supported by the observation of a $242(2 \times 2)$ LEED pattern for a saturated glycine layer on $\operatorname{Pt}\{111\}^{44}$ and a $(2 \times 2)$-like for a saturated layer of alanine on $\mathrm{Cu}\{111\} 243$ observed by STM. ${ }^{69}$ It should be noted, however, that no 244 superstructure was observed in LEED for any of the L-alanine 245 layers on $\mathrm{Ni}\{111\}$ prepared in this work.

Molecular Orientation. Figure 3 shows O and N K-edge 247 NEXAFS spectra of alanine layers on $\mathrm{Ni}\{111\}$ close to saturation 248 coverage $(\Theta=0.25 \mathrm{ML})$ recorded at $250 \mathrm{~K}$ with the $\mathrm{X}$-ray beam 249 at $0^{\circ}$ and $65^{\circ}$ with respect the surface normal. Carbon K-edge 250 NEXAFS data were also recorded (see the Supporting 251 Information); however, strong background features overlapping 252 with the adsorbate signal do not allow a quantitative analysis of 253 these spectra.

The oxygen K-edge spectra (Figure 3a,b) exhibit four peaks. 255 The $\pi^{*}$ resonance consists of two peaks at 532.1 and $532.9 \mathrm{eV}, 256$ which are attributed to $\mathrm{COO}$ groups of intact alanine in two 257 different conformations. Figure $3 \mathrm{~b}$ highlights the fact that the 258 maximum of the $\pi^{*}$ resonance is blue-shifted by $0.15 \mathrm{eV}$ from the 259 $65^{\circ}$ to the $0^{\circ}$ spectra, confirming that the resonance consists of 260 two distinct peaks with different angle dependencies. The 261 angular dependencies of the high and low energy peaks, 262 respectively, return tilt angles of the $\mathrm{COO}$ groups of $56^{\circ}$ and 263 $64^{\circ}$ to the surface (see the Supporting Information and ref 70 for 264 details). In addition, two broad $\sigma$ resonances can be resolved at 265 539.0 and $543.2 \mathrm{eV}$, which are attributed to $\mathrm{C}-\mathrm{C}$ and $\mathrm{C}-\mathrm{O} 266$ bonds in accordance with the assignments made for glycine and 267 alanine on $\mathrm{Cu}\{110\} .{ }^{19,28}$

Figure $3 c$ shows nitrogen K-edge NEXAFS spectra. The main 269 peak at $405.5 \mathrm{eV}$ is assigned to a $\sigma(\mathrm{C}-\mathrm{N})$ shape resonance. ${ }^{19,28,45} 270$ The weak peak at $399.5 \mathrm{eV}$ is assigned to a $\pi^{*}$ transition of $\mathrm{C}=\mathrm{N} 271$ decomposition fragments, in agreement with prior work 272 identifying X-ray induced decomposition fragments of amino 273 acids. $^{28,71,72}$ Such low energy peaks are also seen to develop as 274 alanine-covered $\mathrm{Cu}$ surfaces are annealed. ${ }^{42}$

275

A broad conclusion from these NEXAFS data is that alanine is 276 adsorbed on the surface in two conformations discriminated by 277 differing tilt angles of the COO plane. It is presumed that these 278 two conformations correspond to tridentate (low tilt angle) and 279 bidentate (high tilt angle) adsorption.

280

Temperature Dependence. Figure 4 summarizes the 281 temperature-programmed XPS experiments examining the 282 behavior of adsorbed alanine during annealing. The TP-XPS 283 diagrams (Figure $4 \mathrm{a}-\mathrm{c}$ ) comprise a series of fast XP spectra 284 recorded as the temperature of the sample was ramped at 285 $0.2 \mathrm{~K} \mathrm{~s}^{-1}$ (5.4 K per spectrum; for examples, see Figure 4d-f) and 286 merged to produce a $2 \mathrm{D}$ plot of temperature vs binding energy, 287 where false color is used to show spectrum intensity. Vertical line 288 profiles taken at fixed binding energies are shown to illustrate 289 the evolution of the chemical state of the adsorbed alanine 290 (Figure $4 \mathrm{~g}-\mathrm{i}$ ).

The behavior starting from multilayer coverage (>0.4 ML), 292 dosed at $200 \mathrm{~K}$, is tracked through the N 1s spectra in 293 Figure 4a,d,g, while the N 1s and C 1s spectra in Figure 4b,e,h 294 and $c, f, i$ show the behavior of the saturated chemisorbed 295 layer $(\Theta=0.25 \mathrm{ML})$ dosed at $250 \mathrm{~K}$. Significant changes take 296 place between 300 and $480 \mathrm{~K}$. Complete decomposition 297 of surface-bound alanine is associated with the appearance 298 of $\mathrm{C} 1 \mathrm{~s}$ and $\mathrm{N} 1 \mathrm{~s}$ peaks at around 283.5 and $397.2 \mathrm{eV}, 299$ respectively. Alanine desorption commences at around $300 \mathrm{~K}, 300$ as the $\mathrm{N} 1 \mathrm{~s}$ peak at binding energy $399.7 \mathrm{eV}$ and the $\mathrm{C} 1$ s peaks 301 at 286.0 and $289.0 \mathrm{eV}$, previously assigned to intact alanine, 302 decrease dramatically, initially without a corresponding 303 growth of the peaks assigned to decomposition products. 304 Decomposition starts at around $320 \mathrm{~K}$ and proceeds to 305 

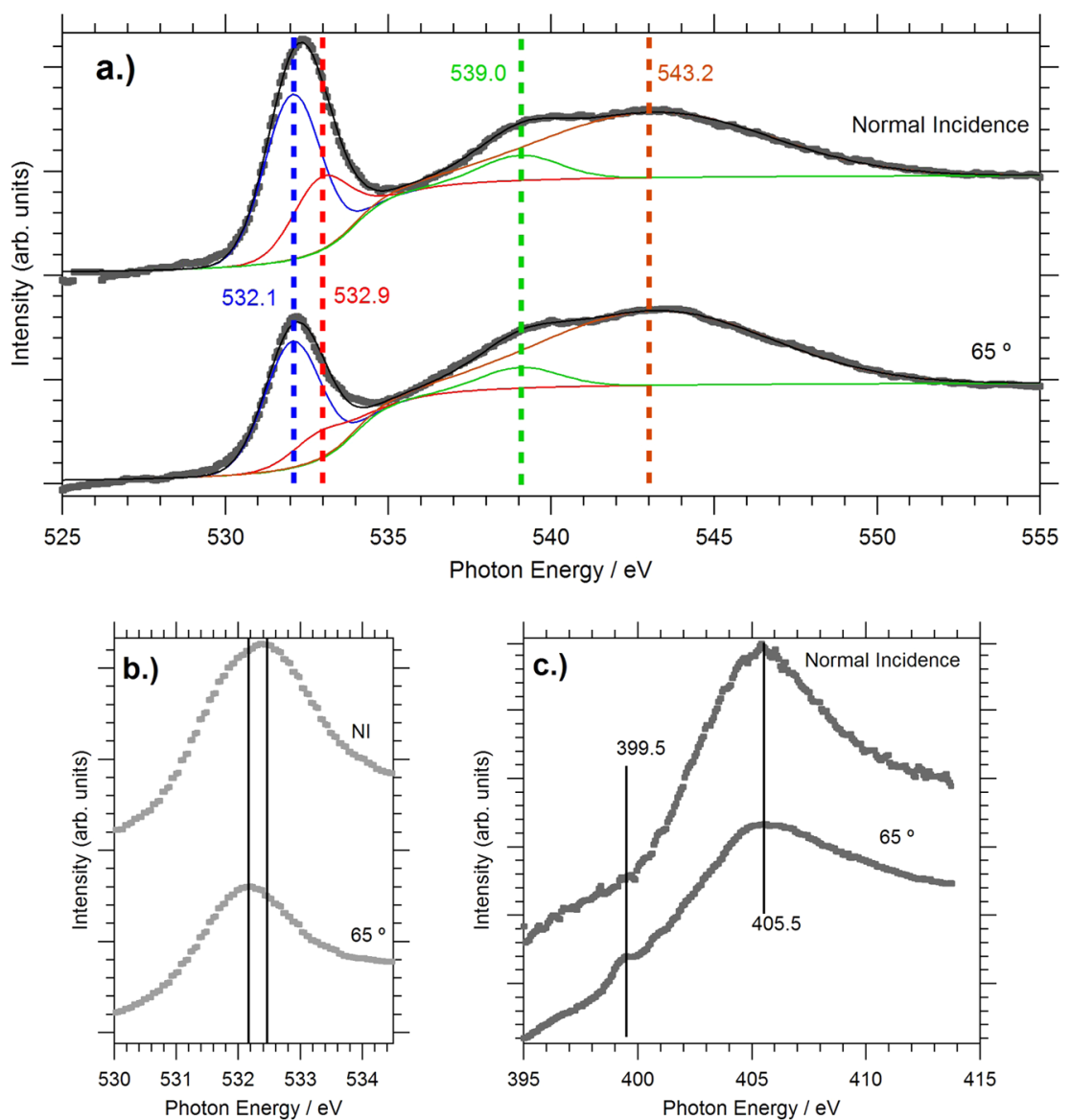

Figure 3. Experimental data (dots) and fits (lines) of Auger yield NEXAFS (a, b: O K-edge data; c: N K-edge data) for a saturated layer of L-alanine on $\mathrm{Ni}\{111\}$ at $250 \mathrm{~K}$. Angles indicated are those between the surface normal and the X-ray beam.

306 completion in at least three steps at $\approx 320 \mathrm{~K}, \approx 380 \mathrm{~K}$, 307 and $\approx 460 \mathrm{~K}$, which are most clearly seen in the $\mathrm{C} 1$ s spectrum 308 (Figure $4 \mathrm{~b}, \mathrm{~h}$ ). Above $480 \mathrm{~K}$, the N 1 s and C 1 s signals cease to 309 change in binding energy or intensity until they disappear 310 completely at $\approx 730 \mathrm{~K}$.

311 Temperature-programmed desorption experiments (see the 312 Supporting Information) show evolution of $\mathrm{H}_{2}$ and $\mathrm{CO}_{2}$ 313 between 300 and $450 \mathrm{~K}$ with two peaks at 350 and $420 \mathrm{~K}$ and 314 two desorption peaks of relative mass 28 , which are assigned to $315 \mathrm{CO}(420 \mathrm{~K})$ and $\mathrm{N}_{2}(570 \mathrm{~K})$. Considering the higher heating rate 316 in the TPD experiments $\left(1 \mathrm{~K} \mathrm{~s}^{-1}\right)$, the desorption/decom317 position processes are expected to be shifted to higher 318 temperatures. We, therefore, correlate the TPD peaks to the 319 changes observed in TP-XPS as follows: $350 \mathrm{~K}$ (TPD) $\leftrightarrow 320 \mathrm{~K}$ 320 (TP-XPS), $420 \mathrm{~K}$ (TPD) $\leftrightarrow 380 \mathrm{~K}$ (TP-XPS), $570 \mathrm{~K}$ (TPD) $\leftrightarrow$ $321460 \mathrm{~K}$ (TP-XPS). The assignment of the mass $28 \mathrm{TPD}$ peaks is 322 based on the observation that there is no oxygen signal visible in 323 XPS above $400 \mathrm{~K}$, whereas a desorption of a small fraction of 324 nitrogen is compatible with the $\mathrm{N}$ 1s signal.

325 The first two decomposition steps include dehydrogenation 326 and lead to the release of hydrogen and the breaking of the $\mathrm{C}-\mathrm{C}$ 327 "backbone" of the amino acid, which is accompanied by the loss 328 of $\mathrm{CO}_{2}$. Both processes occur in parallel; however, the different 329 relative intensities in the $\mathrm{H}_{2}$ and $\mathrm{CO}_{2}$ desorption features 330 indicate that dehydrogenation dominates in the first step, leaving 331 behind an intermediate, which undergoes $\mathrm{C}-\mathrm{C}$ bond scission in 332 the second step. Overall, the surface reaction taking place between 300 and $400 \mathrm{~K}$ is 333

$$
\begin{aligned}
& \text { OOC- } \mathrm{CH}\left(\mathrm{CH}_{3}\right)\left(\mathrm{NH}_{2}\right)_{(\mathrm{ads})} \\
& \rightarrow \mathrm{H}_{x} \mathrm{C}_{2} \mathrm{~N}_{(\mathrm{ads})}+\mathrm{CO}_{2(\mathrm{~g})}+\left(3-\frac{x}{2}\right) \mathrm{H}_{2(\mathrm{~g})}
\end{aligned}
$$

Figure 4g,h,i shows that the integrated area under the N 1s XPS 334 signal does not change much above $350 \mathrm{~K}$, whereas the inte- 335 grated C 1 s signal falls by more than $50 \%$ between 350 and $480 \mathrm{~K}, 336$ supporting the above mechanism. The amine residue will then 337 undergo sequential loss of hydrogen until a highly unsaturated 338 hydrocarbon is left on the surface. This transition causes the 339 changes in binding energy seen around $460 \mathrm{~K}$. Figure $4 \mathrm{~h}$ shows a 340 drop to $56 \%$ in the integrated $\mathrm{N} 1 \mathrm{~s}$ signal ( $1 / 1.8$ of the initial inten- 341 sity) for the saturated chemisorbed layer between 300 and $500 \mathrm{~K}, 342$ whereas the integrated $\mathrm{C} 1 \mathrm{~s}$ drops to $34 \%$ (1/2.9 in Figure $4 \mathrm{i}) .343$ Considering that the $\mathrm{C}: \mathrm{N}$ ratio for intact alanine (at $300 \mathrm{~K}$ ) is 3:1 344 and disregarding possible intensity variations due to diffraction 345 effects, this would lead to a C:N ratio of 2:1 after complete 346 decomposition. The $\mathrm{C} 1 \mathrm{~s}$ and $\mathrm{N} 1 \mathrm{~s}$ signals of the decomposition 347 products disappear at the same temperature, $730 \mathrm{~K}\left(\mathrm{~N}_{2}\right.$ desorbs 348 into the gas phase, and $\mathrm{C}$ dissolves into the $\mathrm{Ni}$ bulk). This is a 349 strong indication that the $\mathrm{C}$ and $\mathrm{N}$ atoms are still associated in a 350 molecular surface species at higher temperatures rather than 351 isolated chemisorbed atoms. Additional support for this 352 assumption comes from the fact that the nitrogen K-edge 353 NEXAFS spectrum of this species is different from published 354 spectra of atomic $\mathrm{N}$ on $\mathrm{Ni}$ surfaces (see Figure $\mathrm{S} 2$ in the 355 Supporting Information and ref 73). An extended N-doped 356 

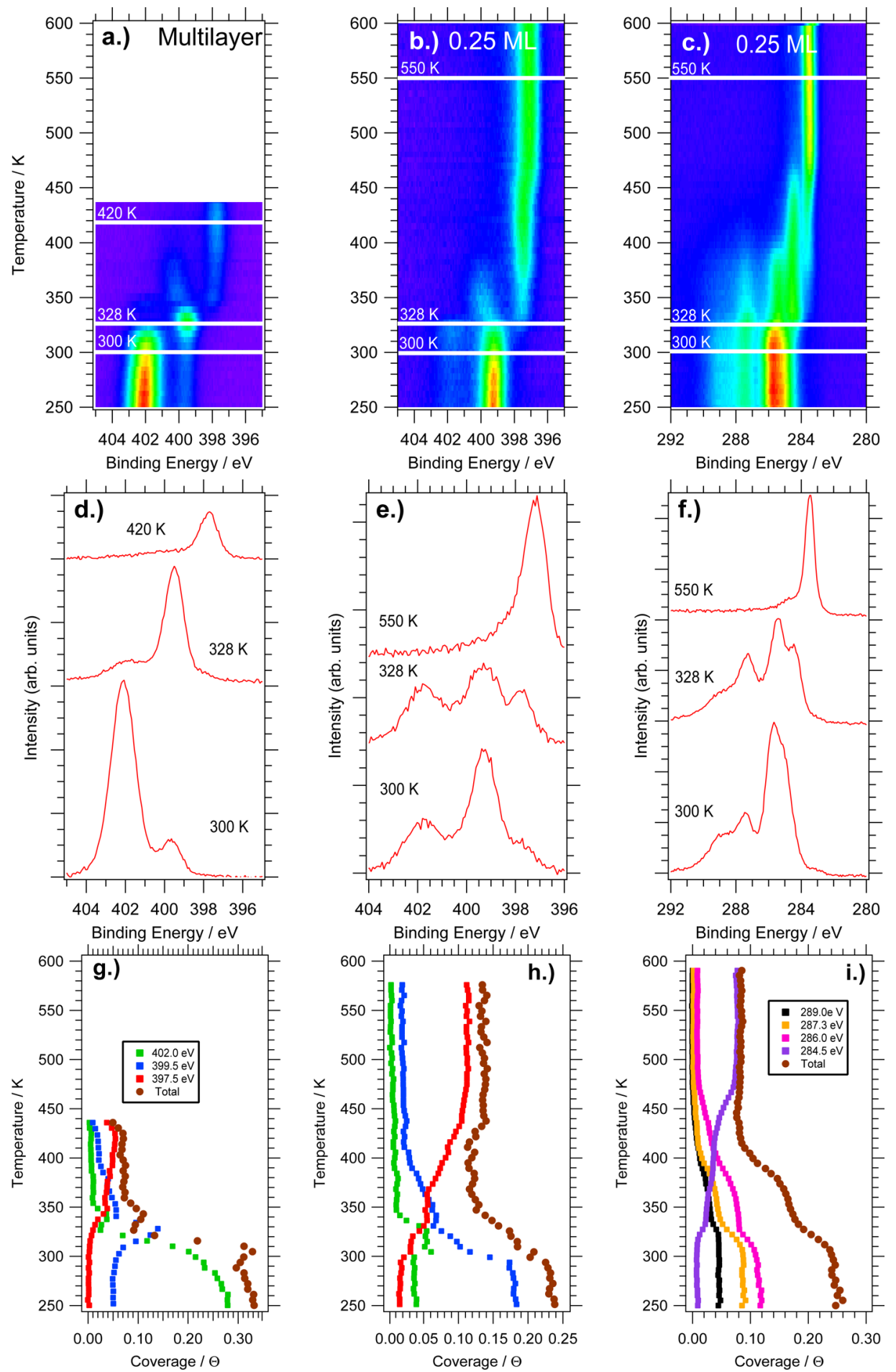

Figure 4. $(a-c)$ TP-XPS data for $L$-alanine adsorbed on $\mathrm{Ni}\{111\},(d-f)$ selected spectra extracted from $(a-c),(g-i)$ integrated line profiles showing integrated intensity in $2 \mathrm{eV}$ wide bands. (a, d, g) N 1s (excitation energy $525 \mathrm{eV}$ ) of $>0.4 \mathrm{ML}$ dosed at $200 \mathrm{~K}$. (b, e, h) N 1s (excitation energy $525 \mathrm{eV}$ ) of $0.25 \mathrm{ML}$ dosed at $250 \mathrm{~K}$. (c.) $\mathrm{C} 1 \mathrm{~s}$ (excitation energy $410 \mathrm{eV}$ ) of $0.25 \mathrm{ML}$ dosed at $250 \mathrm{~K}$. Heating rate $\beta=0.2 \mathrm{~K} \mathrm{~s}^{-1}$; data acquisition time per spectrum, $27 \mathrm{~s}$.

357 graphene-like $\mathrm{C}_{y}$-N network can be excluded as the XPS binding 358 energies reported for such structures are in the ranges of 284.5$359285.0 \mathrm{eV}$ (C 1s) and 398.7-400.7 eV (N 1s), i.e., significantly 360 higher than the ones found here, and they are stable up to $>900 \mathrm{~K}^{74}$

361

\section{CONCLUSIONS AND SUMMARY}

362 Thermal decomposition of small amino acids, such as alanine and 363 glycine, has previously been observed on a suite of surfaces by means of TPD and TP-XPS, including $\mathrm{Cu}\{111\},{ }^{45} \mathrm{Cu}\{110\},{ }^{7,42} 364$ $\mathrm{Cu}\{531\},{ }^{39} \mathrm{Pt}\{111\},{ }^{41,44}$ and $\mathrm{Pd}\{111\} .^{32,33}$ In all surveyed cases, 365 decomposition proceeds via a $\beta$-hydride elimination step (or 366 possibly $\gamma$-elimination in the case of alanine) prior to $\mathrm{C}-\mathrm{C}$ bond 367 scission between the carboxylate and the $\alpha$-carbon, which leads 368 to the release of $\mathrm{H}_{2}$ and $\mathrm{CO}_{2}$ into the gas phase. This is followed 369 by sequential dehydrogenation and collapse of the alkyl amine, 370 releasing $\mathrm{H}_{2}$ into the gas phase. From the list of decomposition 371 temperatures in Table 1 , it is clear that $\mathrm{Ala} / \mathrm{Ni}\{111\}$, alongside 372 
Table 1. Onset of Decomposition for Glycine and Alanine Adsorbed on Different Single Crystal Surfaces under UHV Conditions

\begin{tabular}{lcll} 
& onset $(\mathrm{K})$ & method & ref \\
$\mathrm{Ala} / \mathrm{Cu}\{111\}$ & 440 & TPD & 45 \\
& 425 & TP-XPS & 45 \\
$\mathrm{Ala} / \mathrm{Cu}\{110\}$ & 500 & TPD & 7 \\
& 470 & TP-XPS & 42 \\
$\mathrm{Ala} / \mathrm{Ni}\{111\}$ & 320 & TP-XPS & this work \\
$\mathrm{Ala} / \mathrm{Pd}\{111\}$ & 350 & TPD & 33 \\
$\mathrm{Gly} / \mathrm{Cu}\{110\}$ & 460 & TP-XPS & 42 \\
$\mathrm{Gly} / \mathrm{Cu}\{531\}$ & 490 & TPD & 39 \\
$\mathrm{Gly} / \mathrm{Pd}\{111\}$ & 320 & TPD & 32 \\
$\mathrm{Gly} / \mathrm{Pt}\{111\}$ & 360 & TPD & 44 \\
& 350 & TP-XPS & 41 \\
\hline
\end{tabular}

$373 \mathrm{Gly} / \mathrm{Pd}\{111\}$, is among the least stable adsorption systems 374 studied so far. The onset of decomposition around $320 \mathrm{~K}$ is more 375 than 100 Klower than that for the close-packed $\mathrm{Cu}\{111\}$ surface. 376 In general, dissociation is far more facile on the group-10 377 transition metals than on $\mathrm{Cu}$. Therefore, $\mathrm{Cu}$ surfaces are not 378 likely to be good models for enantioselective modification of the $379 \mathrm{Ni}, \mathrm{Pd}$, or Pt catalysts that are used in enantioselective 380 hydrogenation reactions. Important in this context is also the 381 fact that the onset of decomposition for $\mathrm{Ala} / \mathrm{Ni}\{111\}$ is within 382 the range of temperatures used for chiral modification of Raney 383 nickel $(273-373 \mathrm{~K})$ and below the typical range of reaction 384 temperatures for the enantioselective hydrogenation of MAA $385(333-343 \mathrm{~K}){ }^{2,3}$ This is a clear indication that the active modifier 386 under reaction conditions is not the intact alaninate surface 387 species that we observed below $320 \mathrm{~K}$ in UHV in the present 388 study. Under reaction conditions, decomposition of alanine may 389 be hindered by the presence of solvent and/or the reactants on 390 the surface; however, this would almost certainly also involve a 391 change in the geometry and bond coordination of the 392 adsorption complex. A recent near-ambient pressure study of $393 \mathrm{Gly} / \mathrm{Pt}\{111\}$ has shown that an aqueous environment up to 3940.2 Torr does not stabilize the intact adsorbate on this system 395 significantly, although the stability and reaction path of the 396 decomposition products change. ${ }^{41}$ Payne et al. ${ }^{75}$ have shown 397 that exposure to water vapor in the range of $10^{9} \mathrm{~L}\left(=10^{3} \mathrm{mbar} \mathrm{s}\right)$ 398 leads to significant surface oxididation on polycrystalline $\mathrm{Ni}$ 399 samples, as one would also expect under catalytic reaction 400 conditions. ${ }^{76}$ Neither the behavior of relevant chiral molecules 401 on Ni oxides nor the influence of other solvents or the reactants 402 of the hydrogenation reaction on the surface chemistry of 403 amino acids have been studied so far. Another possibility is 404 that the $\mathrm{H}_{x} \mathrm{C}_{2} \mathrm{~N}_{(\text {ads })}$ surface species resulting from the first 405 decomposition step is the actual modifier. This species is not 406 chiral, but it could stabilize a chiral reconstruction of the $\mathrm{Ni}$ 407 surface and/or form a chiral complex with the solvent or one of 408 the reactants.

409 In summary, the chemical sate and molecular orientation 410 of L-alanine on $\mathrm{Ni}\{111\}$ have been investigated between 250 and $411600 \mathrm{~K}$. Synchrotron-based XPS and NEXAFS spectroscopy show 412 that alanine is adsorbed in both the anionic (tridentate) and the 413 zwitterionic (bidentate) states up to room temperature, with 414 both states coexisting in the saturated layer. The chemisorbed 415 layer saturates at $\Theta=0.25 \mathrm{ML}$. At low coverages, decomposition 416 of the alanine molecule is significant even at $250 \mathrm{~K}$; however, at 417 higher coverages, surface congestion appears to prevent break up 418 of the molecule. Desorption and decomposition begin together at $\approx 300 \mathrm{~K}$, with decomposition occurring in a multistep process 419 up to $450 \mathrm{~K}$.

\section{ASSOCIATED CONTENT}

\section{S Supporting Information}

421

The Supporting Information is available free of charge on the 423 ACS Publications website at DOI: 10.1021/acs.jpcc.5b08814. 424 Data analysis and additional data (PDF) 425

\section{AUTHOR INFORMATION}

426

Corresponding Author

427

*Phone: +44 (0)118 3784367. Fax: +44 (0)118 3786331. 428 E-mail: g.held@reading.ac.uk.

429

\section{Notes}

The authors declare no competing financial interest.

\section{ACKNOWLEDGMENTS}

432

The research leading to these results has received funding 433 from the U.K.'s EPSRC through grants EP/G068593/1 and 434 EP/F02116X/1, the European Community's Seventh Frame- 435 work Programme (FP7/2007-2013) CALIPSO under grant 436 agreement No. 312284, and the Marie Curie Training Network 437 SMALL funded by the European Community's Seventh 438 Framework under grant agreement No. 238804. The authors 439 thank the staff of ALS and MAXlab for their help during the 440 experiments.

\section{REFERENCES}

442

(1) Fukawa, H.; Izumi, Y.; Komatsu, S.; Akabori, S. Studies on modified 443 hydrogenation catalyst. I. Selective hydrogenation activity of modified 444 Raney nickel catalyst for carbonyl group and $\mathrm{C}=\mathrm{C}$ double bond. Bull. 445 Chem. Soc. Jpn. 1962, 35, 1703-1706.

446

(2) Izumi, Y. Modified Raney Nickel (MRNi) Catalyst: Heterogeneous 447 enantio-differentiating (asymmetric) catalyst. Adv. Catal. 1983, 32, 448 215-271.

449

(3) Keane, M. A. Adsorption of optically pure alanine on silica- 450 supported nickel and the consequent catalytic enantioselectivity. 451 Langmuir 1994, 10, 4560-4565.

(4) Baddeley, C. J. Fundamental investigations of enantioselective 453 heterogeneous catalysis. Top. Catal. 2003, 25, 17-28.

(5) Nitta, Y.; Sekine, F.; Imanaka, T.; Teranishi, S. The effect of 455 crystallite size of nickel on the enantioselectivity of modified nickel 456 catalysts. Bull. Chem. Soc. Jpn. 1981, 54, 980-984.

(6) Wolfson, A.; Geresh, S.; Landau, M. V.; Herskowitz, M. 458 Enantioselective hydrogenation of methyl acetoacetate catalyzed by 459 nickel supported on activated carbon or graphite. Appl. Catal., A 2001, 460 208, 91-98.

461

(7) Barlow, S. M.; Louafi, S.; Le Roux, D.; Williams, J.; Muryn, C.; Haq, 462 S.; Raval, R. Polymorphism in supramolecular chiral structures of R- and 463 S-alanine on $\mathrm{Cu}(110)$. Surf. Sci. 2005, 590, 243-263.

464

(8) Williams, J.; Haq, S.; Raval, R. The bonding and orientation of the 465 amino acid L-alanine on $\mathrm{Cu}\{110\}$ determined by RAIRS. Surf. Sci. 1996, 466 368, 303-309.

467

(9) Löfgren, P.; Krozer, A.; Lausmaa, J.; Kasemo, B. Glycine on 468 Pt(111): a TDS and XPS study. Surf. Sci. 1997, 370, 277-292. 469

(10) Barlow, S. M.; Kitching, K. J.; Haq, S.; Richardson, N. V. A study 470 of glycine adsorption on a $\mathrm{Cu}\{110\}$ surface using RAIRS. Surf. Sci. 1998, 471 401, 322-335.

(11) Booth, N. A.; Woodruff, D. P.; Schaff, O.; Gießel, T.; Lindsay, R.; 473 Baumgärtel, P.; Bradshaw, A. M. Determination of the local structure of 474 glycine adsorbed on $\mathrm{Cu}(110)$. Surf. Sci. 1998, 397, 258-264. 475

(12) Zhao, X.; Rodriguez, J. Photoemission study of glycine adsorption 476 on $\mathrm{Cu} / \mathrm{Au}(111)$ interfaces. Surf. Sci. 2006, 600, 2113-2121. 477

(13) Zhao, X.; Yan, H.; Zhao, R. G.; Yang, W. S. Self-assembled 478 structures of glycine on $\mathrm{Cu}(111)$. Langmuir 2003, 19, 809-813. 479 
480 (14) Zhao, X.; Gai, Z.; Zhao, R. G.; Yang, W. S.; Sakurai, T. Adsorption 481 of glycine on $\mathrm{Cu}(001)$ and related step faceting and bunching. Surf. Sci. 482 1999, 424, L347-L351.

483 (15) Zhao, X.; Zhao, R. G.; Yang, W. S. Adsorption of alanine on $484 \mathrm{Cu}(001)$ studied by scanning tunneling microscopy. Surf. Sci. 1999, 442, 485 L995-L1000.

486 (16) Chen, Q.; Frankel, D. J.; Richardson, N. V. Chemisorption induce 487 chirality: glycine on $\mathrm{Cu}\{110\}$. Surf. Sci. 2002, 497, 37-46.

488 (17) Chen, Q.; Frankel, D. J.; Richardson, N. V. The formation of 489 enantiospecific phases on a $\mathrm{Cu}\{110\}$ surface. PhysChemComm 1999, 9, 490 41-44.

491 (18) Kühnle, A.; Linderoth, T. R.; Besenbacher, F. Self-assembly of 492 monodispersed, chiral nanoclusters of cysteine on the $\mathrm{Au}(110)-(1 \times 2)$ 493 Surface. J. Am. Chem. Soc. 2003, 125, 14680-14681.

494 (19) Hasselström, J.; Karis, O.; Weinelt, M.; Wassdahl, N.; Nilsson, A.; 495 Nyberg, M.; Pettersson, L. G. M.; Samant, M. G.; Stöhr, J. The 496 adsorption structure of glycine adsorbed on $\mathrm{Cu}(110)$ : comparison with 497 formate and acetate/Cu(110). Surf. Sci. 1998, 407, 221-236.

498 (20) Nyberg, M.; Hasselström, J.; Karis, O.; Wassdahl, N.; Weinelt, M.; 499 Nilsson, A.; Pettersson, L. G. M. The electronic structure and surface 500 chemistry of glycine adsorbed on $\mathrm{Cu}(110)$. J. Chem. Phys. 2000, 112, $5015420-5427$.

502 (21) Sayago, D. I.; Polcik, M.; Nisbet, G.; Lamont, C. L. A.; Woodruff, 503 D. P. Local structure determination of a chiral adsorbate: Alanine on $504 \mathrm{Cu}(110)$. Surf. Sci. 2005, 590, 76-87.

505 (22) Gonella, G.; Terreni, S.; Cvetko, D.; Cossaro, A.; Mattera, L.; 506 Cavalleri, O.; Rolandi, R; Morgante, A.; Floreano, L.; Canepa, M. 507 Ultrahigh vacuum deposition of L-cysteine on $\mathrm{Au}(110)$ studied by high508 resolution X-ray photoemission: from early stages of adsorption to 509 molecular organization. J. Phys. Chem. B 2005, 109, 18003-18009.

510 (23) Ihs, A.; Liedberg, B.; Uvdal, K.; Tornkvist, C.; Bodo, P.; 511 Lundstrom, I. Infrared and photoelectron-spectroscopy of amino-acids 512 on copper - glycine, L-alanine and beta-alanine. J. Colloid Interface Sci. 513 1990, 140, 192-206.

514 (24) Uvdal, P.; Bodo, P.; Liedberg, B. L-cysteine adsorbed on gold and 515 copper - an X-ray photoelectron-spectroscopy study. J. Colloid Interface 516 Sci. 1992, 149, 162-173.

517 (25) Iwai, H.; Egawa, C. Molecular orientation and intermolecular 518 interaction in alanine on $\mathrm{Cu}(001)$. Langmuir 2010, 26, 2294-2300.

519 (26) Iwai, H.; Tobisawa, M.; Emori, A.; Egawa, C. STM study of D520 alanine adsorption on $\mathrm{Cu}(001)$. Surf. Sci. 2005, 574, 214-218.

521 (27) Gladys, M. J.; Stevens, A. V.; Scott, N. R.; Jones, G.; Batchelor, D.; 522 Held, G. Enantiospecific adsorption of alanine on the chiral $\mathrm{Cu}(531)$ 523 surface. J. Phys. Chem. C 2007, 111, 8331-8336.

524 (28) Jones, G.; Jones, L. B.; Thibault-Starzyk, F.; Seddon, E. A.; Raval, 525 R.; Jenkins, S. J.; Held, G. The local adsorption geometry and electronic 526 structure of alanine on $\mathrm{Cu}\{110\}$. Surf. Sci. 2006, 600, 1924-1935.

527 (29) Jones, T. E.; Baddeley, C. J.; Gerbi, A.; Savio, L.; Rocca, M.; 528 Vattuone, L. Molecular ordering and adsorbate induced faceting in the 529 Ag110-(S)-glutamic acid system. Langmuir 2005, 21, 9468-9475.

530 (30) Jones, T. E.; Urquhart, M. E.; Baddeley, C. J. An investigation of 531 the influence of temperature on the adsorption of the chiral modifier, 532 (S)-glutamic acid, on Ni\{111\}. Surf. Sci. 2005, 587, 69-77.

533 (31) Gao, F.; Wang, Y.; Burkholder, L.; Tysoe, W. T. Chemistry of L534 proline on $\operatorname{Pd}\{111\}$ : TPD and XPS study. Surf. Sci. 2007, 601, 35795353588.

536 (32) Gao, F.; Li, Z.; Wang, Y.; Burkholder, L.; Tysoe, W. T. Chemistry 537 of glycine on $\operatorname{Pd}(111)$ : temperature programmed desorption and $\mathrm{X}$-ray 538 photoelectron spectroscopic study. J. Phys. Chem. C 2007, 111, 99815399991.

540 (33) Gao, F.; Li, Z.; Wang, Y.; Burkholder, L.; Tysoe, W. T. Chemistry 541 of alanine on $\operatorname{Pd}(111)$ : temperature programmed desorption and $\mathrm{X}$-ray 542 photoelectron spectroscopic study. Surf. Sci. 2007, 601, 3276-3288.

543 (34) Mahapatra, M.; Burkholder, L.; Bai, Y.; Garvey, M.; Boscoboinik, 544 J. A.; Hirschmugl, C.; Tysoe, W. T. Formation of chiral self-assembled 545 structures of amino acids on transition-metal surfaces: alanine on $\mathrm{Pd}$ 546 (111). J. Phys. Chem. C 2014, 118, 6856-6865.
(35) Thomsen, L.; Tadich, A.; Riley, D. P.; Cowie, B. C. C.; Gladys, M. 547 J. Investigating the Enantioselectivity of Alanine on a Chiral 548 $\mathrm{Cu}\{421\}(\mathrm{R})$ Surface. J. Phys. Chem. C 2012, 116, 9472-9480.

549

(36) Thomsen, L.; Wharmby, M.; Riley, D. P.; Held, G.; Gladys, M. J. 550 The adsorption and stability of sulfur containing amino acids on 551 $\mathrm{Cu}\{531\}$. Surf. Sci. 2009, 603, 1253-1261.

552

(37) Schiffrin, A.; Riemann, A.; Auwärter, W.; Pennec, Y.; Weber- 553 Bargioni, A.; Cvetko, D.; Cossaro, A.; Morgante, A.; Barth, J. V. 554 Zwitterionic self-assembly of L-methionine nanogratings on the 555 $\mathrm{Ag}(111)$ surface. Proc. Natl. Acad. Sci. U. S. A. 2007, 104, 5279-5284. 556

(38) Eralp, T.; Cornish, A.; Shavorskiy, A.; Held, G. The study of chiral 557 adsorption systems using synchrotron-based structural and spectro- 558 scopic techniques: stereospecific adsorption of serine on Au-modified 559 chiral $\mathrm{Cu}\{531\}$ surfaces. Top. Catal. 2011, 54, 1414-1428. 560

(39) Eralp, T.; Zheleva, Z. V.; Shavorskiy, A.; Dhanak, V. R.; Held, G. 561 Adsorption geometry of glycine on the intrinsically chiral $\mathrm{Cu}\{531\} 562$ surface. Langmuir 2010, 26, 10918-10923.

563

(40) Eralp, T.; Shavorskiy, A.; Zheleva, Z. V.; Held, G.; Kalashnyk, N.; 564 Ning, Y.; Linderoth, T. R. Global and local chiral resolution of serine on 565 the $\mathrm{Cu}\{110\}$ surface. Langmuir 2010, 26, 18841-18851. 566

(41) Shavorskiy, A.; Eralp, T.; Schulte, K.; Bluhm, H.; Held, G. Surface 567 chemistry of glycine on $\mathrm{Pt}\{111\}$ in different aqueous environments. Surf. 568 Sci. 2013, 607, 10-19.

(42) Shavorskiy, A.; Aksoy, F.; Grass, M. E.; Liu, Z.; Bluhm, H.; Held, 570 G. A step toward the wet surface chemistry of glycine and alanine on 571 $\mathrm{Cu}\{110\}$ : destabilization and decomposition in the presence of near- 572 ambient water vapor. J. Am. Chem. Soc. 2011, 133, 6659-6667. 573

(43) Inoue, Y.; Okabe, K.; Yasumori, I. X-ray photoelectron spectra of 574 adsorbed methyl acetoacetate and coordinated tartaric acid, aspartic acid 575 and alanine on the nickel surface. Bull. Chem. Soc. Jpn. 1981, 54, 613- 576 614.

(44) Ernst, K. H.; Christmann, K. The interaction of glycine with a 578 platinum (111) surface. Surf. Sci. 1989, 224, 277-310. 579

(45) Baldanza, S.; Cornish, A.; Nicklin, R. E.; Zheleva, Z. V.; Held, G. 580 Surface chemistry of alanine on $\mathrm{Cu}\{111\}$ : Adsorption geometry and 581 temperature dependence. Surf. Sci. 2014, 629, 114-122.

(46) Efstathiou, V.; Woodruff, D. Characterisation of the interaction of 583 glycine with $\mathrm{Cu}(110)$ and $\mathrm{Cu}(111)$. Surf. Sci. 2003, 531, 304-318. 584

(47) Kang, J.-H.; Toomes, R. L.; Polcik, M.; Kittel, M.; Hoeft, J.-T.; 585 Efstathiou, V.; Woodruff, D. P.; Bradshaw, A. M. Structural investigation 586 of glycine on $\mathrm{Cu}(100)$ and comparison to glycine on $\mathrm{Cu}(110)$. J. Chem. 587 Phys. 2003, 118, 6059-6071.

(48) Rankin, R. B.; Sholl, D. S. First-principles studies of chiral step 589 reconstructions of $\mathrm{Cu}(100)$ by adsorbed glycine and alanine. J. Chem. 590 Phys. 2006, 124, 074703-1-6.

591

(49) Rankin, R. B.; Sholl, D. S. Assessment of heterochiral and 592 homochiral glycine adlayers on $\mathrm{Cu}\left(\begin{array}{lll}1 & 1 & 0\end{array}\right)$ using density functional 593 theory. Surf. Sci. 2004, 548, 301-308.

(50) Rankin, R. B.; Sholl, D. S. Structure of enantiopure and racemic 595 alanine adlayers on $\mathrm{Cu}(110)$. Surf. Sci. 2005, 574, L1-L8. 596

(51) Rankin, R. B.; Sholl, D. S. Structures of glycine, enantiopure 597 alanine, and racemic alanine adlayers on $\mathrm{Cu}(110)$ and $\mathrm{Cu}(100)$ surfaces. 598 J. Phys. Chem. B 2005, 109, 16764-16773.

599

(52) Barlow, S. M.; Raval, R. Complex organic molecules at metal 600 surfaces: bonding, organisation and chirality. Surf. Sci. Rep. 2003, 50, 601 201-341.

602

(53) Raval, R. Nanoscale insights into the creation of chiral surfaces. J. 603 Mol. Catal. A: Chem. 2009, 305, 112-116.

(54) Ghiringhelli, L. M.; Schravendijk, P.; Delle Site, L. Adsorption of 605 alanine on a $\mathrm{Ni}(111)$ surface: A multiscale modeling oriented density 606 functional study. Phys. Rev. B: Condens. Matter Mater. Phys. 2006, 74, 607 035437.

608

(55) Nyholm, R.; Andersen, J. N.; Johansson, U.; Jensen, B. N.; Lindau, 609 I. Beamline I311 at MAX-LAB: a VUV/soft X-ray undulator beamline 610 for high resolution electron spectroscopy. Nucl. Instrum. Methods Phys. 611 Res., Sect. A 2001, 467-468, 520-524.

(56) Grass, M. E.; Karlsson, P. G.; Aksoy, F.; Lundqvist, M.; Wannberg, 613 B.; Mun, B. S.; Hussain, Z.; Liu, Z. New ambient pressure photoemission 614 
615 endstation at Advanced Light Source beamline 9.3.2. Rev. Sci. Instrum. 616 2010, 81, 053106-1-7.

617 (57) Held, G.; Schuler, J.; Sklarek, W.; Steinrück, H.-P. Determination 618 of adsorption sites of pure and coadsorbed $\mathrm{CO}$ on $\mathrm{Ni}(111)$ by high 619 resolution X-ray photoelectron spectroscopy. Surf. Sci. 1998, 398, 154620171.

621 (58) Carley, A. F.; Chinn, M.; Parkinson, C. R. The adsorption and 622 oxidation of cyanogen on copper surfaces. Surf. Sci. 2003, 537, 64-74. 623 (59) Carley, A. F.; Chinn, M.; Parkinson, C. R. Polymerisation of 624 cyanogen on graphite and copper films. Surf. Sci. 2002, 517, L563625 L567.

626 (60) Fleming, G.; Adib, K.; Rodriguez, J.; Barteau, M.; White, J.; Idriss, $627 \mathrm{H}$. The adsorption and reactions of the amino acid proline on rutile $628 \mathrm{TiO} 2(1 ; 1 ; 0)$ surfaces. Surf. Sci. 2008, 602, 2029-2038.

629 (61) Lorenz, M.; Fuhrmann, T.; Streber, R.; Bayer, A.; Bebensee, F.; 630 Gotterbarm, K.; Kinne, M.; Traenkenschuh, B.; Zhu, J. F.; Papp, C.; et al. 631 Ethene adsorption and dehydrogenation on clean and oxygen 632 precovered $\mathrm{Ni}(111)$ studied by high resolution $\mathrm{x}$-ray photoelectron 633 spectroscopy. J. Chem. Phys. 2010, 133, 014706.

634 (62) Papp, C.; Denecke, R.; Steinrück, H.-P. Adsorption and reaction 635 of cyclohexene on a $\mathrm{Ni}(111)$ surface. Langmuir 2007, 23, 5541-5547. 636 (63) Papp, C.; Fuhrmann, T.; Tränkenschuh, B.; Denecke, R.; 637 Steinrück, H.-P. Kinetic isotope effects and reaction intermediates in the 638 decomposition of methyl on flat and stepped platinum (111) surfaces. 639 Chem. Phys. Lett. 2007, 442, 176-181.

640 (64) Steinrück, H.-P.; Fuhrmann, T.; Papp, C.; Traenkenschuh, B.; 641 Denecke, R. A detailed analysis of vibrational excitations in X-ray 642 photoelectron spectra of adsorbed small hydrocarbons. J. Chem. Phys. 643 2006, 125, 204706.

644 (65) Zhao, Q.; Deng, R.; Zaera, F. Thermal activation and reaction of 645 allyl alcohol on $\mathrm{Ni}(100)$. Surf. Sci. 2011, 605, 1236-1242.

646 (66) Zhao, Q.; Deng, R.; Zaera, F. Formation of an oxametallacycle 647 surface intermediate via thermal activation of 1-chloro-2-methyl-2648 propanol on $\mathrm{Ni}(100)$. J. Phys. Chem. C 2010, 114, 7913-7919.

649 (67) Castonguay, M.; Roy, J.-R.; McBreen, P. H. Sequential selective 650 formation of adsorbed tert-butoxy and tert-butyl groups from tert-butyl 651 formate on $\mathrm{Ni}(111)$. Langmuir 2000, 16, 8306-8310.

652 (68) Chen, J. J.; Winograd, N. The adsorption and decomposition of 653 methylamine on $\operatorname{Pd}\{111\}$. Surf. Sci. 1995, 326, 285-300.

654 (69) Ge, S.-P.; Lü, C.; Zhao, R.-G. Adsorption of L-alanine on $\mathrm{Cu}(111)$ 655 studied by scanning tunnelling microscopy. Chin. Phys. Lett. 2006, 23, $6561558-1561$.

657 (70) Stöhr, J. NEXAFS Spectroscopy; Springer Series in Surface 658 Sciences; Springer: Berlin, 1996.

659 (71) Zubavichus, Y.; Fuchs, O.; Weinhardt, L.; Heske, C.; Umbach, E.; 660 Denlinger, J. D.; Grunze, M. Soft X-ray-induced decomposition of 661 amino acids: An XPS, mass spectrometry, and NEXAFS study. Radiat. 662 Res. 2004, 161, 346-358.

663 (72) Zubavichus, Y.; Shaporenko, A.; Grunze, M.; Zharnikov, M. 664 Innershell absortpion spectroscopy of amino acids at all relevant 665 absorption edges. J. Phys. Chem. A 2005, 109, 6998-7000.

666 (73) Zdansky, E. O. F.; Nilsson, A.; Tillborg, H.; Björneholm, O.; 667 MÅrtensson, N.; Andersen, J. N.; Nyholm, R. Electronic structure of 668 atomic adsorbates from x-ray-absorption spectroscopy: Threshold 669 effects and higher excited states. Phys. Rev. B: Condens. Matter Mater. 670 Phys. 1993, 48, 2632-2648.

671 (74) Zhao, W.; Höfert, O.; Gotterbarm, K.; Zhu, J.; Papp, C.; 672 Steinrück, H.-P. Production of nitrogen-doped graphene by low-energy 673 nitrogen implantation. J. Phys. Chem. C 2012, 116, 5062-5066.

674 (75) Payne, B. P.; Biesinger, M. C.; McIntyre, N. S. The study of 675 polycrystalline nickel metal oxidation by water vapour. J. Electron 676 Spectrosc. Relat. Phenom. 2009, 175, 55-65.

677 (76) Sugimura, T.; Matsuda, T.; Osawa, T. Synthesis of optically active 678 methyl 4-(4-biphenylyl)-3-hydroxybutanoate via enantioselective hy679 drogenation using a tartaric acid-modified nickel catalyst and 680 recrystallization. Tetrahedron: Asymmetry 2009, 20, 1877-1880. 